\title{
Socioeconomic and demographic trends in the prevalence of type 2 diabetes in India
}

\author{
Bikrant Kumar Kindo, Rana Himanshu' ${ }^{1}$, K. Parmar ${ }^{2}$, S. Dube ${ }^{3}$, J. Ramesh ${ }^{4}$ \\ MD Medicine, Additional Director NCD, Government of Odisha, Odisha, ${ }^{1}$ Associate Professor of Medicine, GMERS Medical College, Gotri, \\ Baroda, ${ }^{2}$ Assistant Professor of Medicine, BJ Medical College, Ahmedabad, ${ }^{3}$ Associate Professor of Medicine, GMC Bhopal, Bhopal, \\ ${ }^{4} \mathrm{HOD}$ Department of General Medicine, Indira Gandhi Government General Hospital and Post-Graduation Institute, Puducherry, India
}

\section{A B S T R A C T}

Noncommunicable diseases (NCDs), also known as chronic diseases, are not passed from person to person.They are of long duration and generally slow progression. The four main types of NCDs are cardiovascular diseases (such as heart attacks and stroke), cancers, chronic respiratory diseases (such as chronic obstructive pulmonary disease and asthma), and diabetes. The rapid demographic and epidemiologic transition that India is facing today is paralleled by a massive increase in NCD prevalence, of which diabetes remains the most dominant. Besides genetic and environmental factors, an increase in life expectancy, urbanization, influenced unhealthy lifestyle changes, affluence associated with dietary excess, and reduced physical activity appear to be major drivers for increased burden of diabetes in India. Inappropriate nutrition and physical inactivity lead to obesity, a positive predictor for diabetes. Moreover, early onset of diabetes accompanied by prevailing poverty, low awareness, and poor health consciousness across socioeconomic and demographic strata is reflected in the large burden of undiagnosed cases of diabetes. In addition, reversal of socioeconomic gradient of disease burden observed in India can have serious health and financial implications on individual and healthcare system, which, if left unaddressed, may result in an adverse impact on the nation's economy. Keeping in view, a major shift in India's burden of disease, there is an imperative need for robust, systematic measures for data reporting supported by effective public healthcare interventions to reduce the burden of diabetes. Comprehensive multisectoral actions prioritizing identification of risk factors, early diagnosis, and effective implementation of cost-effective interventions can curb the epidemic of diabetes.A multifaceted approach for implementation of evidence-based policy measures involving various departments of the government and nongovernmental agencies is required to address both preventive and curative aspects of diabetes management. Policies that ensure better surveillance and increase in access to affordable and essential medicines providing universal health coverage should be developed. Policymakers should take lead in the development or strengthening the existing policies and see that they are not only implemented but also evaluated for their effectiveness.A strong commitment from both public and private sectors toward implementation and intensification of population-based prevention strategies through proven programs and policies is required to address the growing burden of diabetes.

Key words: Awareness, demography, diabetes, prevalence, socioeconomic factors, socioeconomic status

\section{INTRODUCTION}

At present, India is experiencing rapid socioeconomic growth that is paralleled by a massive increase in

\begin{tabular}{|l|l|}
\hline \multicolumn{2}{|c|}{ Access this article online } \\
\hline Quick Response Code: & Website: \\
\hline & www.joshd.net \\
\hline & \\
\hline
\end{tabular}

diabetes prevalence. Rapid economic growth is linked to epidemiological transitions associated with increased

This is an open access article distributed under the terms of the
Creative Commons Attribution-NonCommercial-ShareAlike 3.0
License, which allows others to remix, tweak, and build upon the
work non-commercially, as long as the author is credited and the
new creations are licensed under the identical terms.
For reprints contact: reprints@medknow.com
$\begin{aligned} & \text { How to cite this article: Kindo BK, Himanshu R, Parmar K, Dube S, } \\ & \text { Ramesh J. Socioeconomic and demographic trends in the prevalence of } \\ & \text { type } 2 \text { diabetes in India. J Soc Health Diabetes 2016;4:90-101. }\end{aligned}$

Corresponding Author: Dr. J. Ramesh, Department of General Medicine, Indira Gandhi Government General Hospital and Post Graduate Institution, Government of Puducherry, Puducherry, India. E-mail: dr_ramji1@yahoo.co.in 


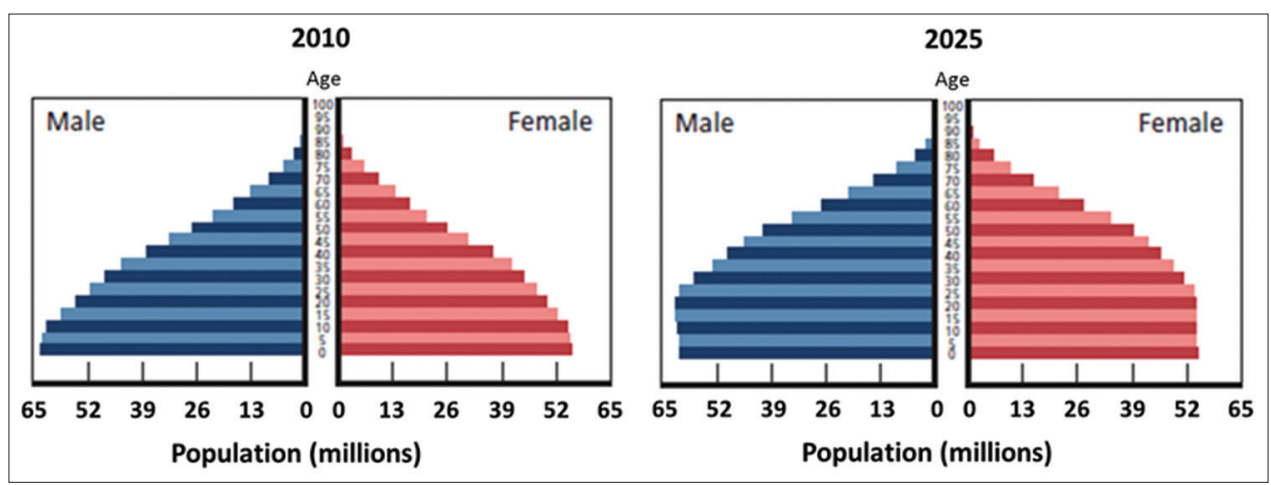

Figure 1: Age-sex structure of the populations of India in 2010 and 2025

life expectancy, lifestyle changes, affluence associated with dietary excess, reduced physical activity, and unplanned urbanization, ${ }^{[1,2]}$ resulting in higher prevalence of diabetes among Indian population. ${ }^{[3]}$ An analysis of Early Detection of Type 2 Diabetes and IGT (DETECT-2) data from Finland, India, the Pacific Islands, and North America showed that the combined effect of demography, age at onset, and mortality could explain only $22 \%$ of the observed $6.2 \%$ increase in diabetes over a 5 -year period in developing regions, while the remaining nearly $80 \%$ of increase in prevalence remains unexplained. ${ }^{[4,5]}$ According to the International Diabetes Federation (IDF), India currently has 69.2 million adults with Type 2 diabetes, second only to China. ${ }^{[6]}$ Furthermore, it is important to include predisposing factors and their impact on the prognosis of diabetes in any analysis of the relative diabetes risk faced by a population or parts of a population.

Contrary to the prevailing belief among policymakers that diabetes primarily afflicts the affluent, the burden of diabetes across all socioeconomic groups is already high and rising with growing uniformity in both urban and rural areas. ${ }^{[7,8]}$ Moreover, urbanization in India is expected to reach $46 \%$ by 2030 ; therefore, it could be expected that in future, there could be substantial increase in the population of patients with diabetes in India. ${ }^{[4]}$ The rising prevalence of diabetes as a result of rapid changes in demographic and socioeconomic factors can have significant economic, societal, clinical, and individual impact. Thus, establishing the predominant risk factors and knowing the sociodemographic patterns of the disease are important not only to understand the underlying etiologies and pathogenetic mechanisms but also to predict future course of epidemic that would help policymakers to design and implement successful treatment strategies to manage diabetes in India. ${ }^{[9]}$

\section{SOCIODEMOGRAPHIC PATTERNING OF DIABETES RISK FACTORS IN INDIA}

Age

The population pyramid for India in 2010 was wider with each birth cohort larger than the one above it, indicating higher fertility rates and larger number of women in their childbearing age. However, the base (ages $0-4$ ) of the pyramid for India in 2025 shrinks reflecting fewer births and increase in number of working-age individuals (20-64 years age group) accounting for $49.8 \%$ of the total population of the country [Figure 1]. ${ }^{[10]}$

Carbohydrate intolerance is common with increasing age. Of the nonmodifiable risk factors for diabetes, a strong association for age was observed in several studies. Most of the studies in the west have attributed increase in insulin resistance for pathogenesis of age-related glucose intolerance in humans while others reported defect of both insulin action and secretion in the elderly. ${ }^{[1,12]}$ Age-related changes in body fat tomography (increase in fat mass and body mass index [BMI] with redistribution of body fat while decrease in bone mineral density, muscle mass, and muscle strength) have important contribution to metabolic consequences in elderly people. DECODA study (Diabetes Epidemiology: Collaborative analysis of Diagnostic criteria in Asia, 2003) evaluated prevalence of diabetes and impaired glucose regulation in four countries by performing serial studies and concluded that Asian Indians have highest prevalence of diabetes in the elderly with the peak at the age of 60-69 years which was $\sim 10$ years younger compared with Chinese and Japanese volunteers. They also observed that impaired glucose tolerance was more prevalent than impaired fasting glycemia in all Asian populations irrespective of age. ${ }^{[13]}$ According to the World Health Organization (WHO), in developing countries such as India, diabetes affects people in their economically 
productive age (20-45 years age-group). ${ }^{[14]}$ It is responsible for 2263 thousands disability adjusted life years (DALYs) and loss of 1157 thousand years of life during year 2004. ${ }^{[16]}$ Ramachandran et al. have reported that the prevalence of diabetes, in patients aged $<40$ years, has increased from $13.9 \%$ in 2000 to $18.6 \%$ in $2006(P<0.0001) .{ }^{[4]}$ Moreover, the ICMR-INDIAB study has demonstrated a significant association of age and diabetes (Odds ratio [OR]: 1.7 [95\% confidence interval [CI], 1.6, 1.8, $P<0.001]$ ) and the prevalence of diabetes has increased between ages 25 and 34 years. ${ }^{[17]}$

Reports from the National Urban Diabetes Survey and Chennai Urban Rural Epidemiology Study (CURES) have suggested a temporal shift in the age at diagnosis of diabetes with the younger population being more affected..$^{[2,18]}$ Similarly, Kumpatla et al. have reported the onset of diabetes at a much younger age in the Indian population compared to previous years $(45 \pm 10.6[2009$ ] vs. $49.9[1999] \pm 9.8$ years, $P<0.0001$ ), with an increase in risk of diabetic complications in later part of their lives. This trend was also observed in South Asians residing in the UK compared to their European counterparts (47 vs. 52.3 years). ${ }^{[19]}$ The genetic phenotype of Asian Indians Phenotype, which is characterized by low BMI, but higher upper body adiposity, higher body fat percentage, and increased propensity for insulin resistance compared to Western population, may be the causal factor. ${ }^{[20]}$

\section{Gender}

The gender ratio is another demographic trend that may have social implications. As per the provisional results of Census 2016, India has one of the most skewed gender ratios at birth in the world with 943 females per 1000 males. ${ }^{[21]}$ Although the age-specific prevalence of diabetes did not differ between men and women, evidence from cross-sectional studies suggests that the odds of suffering from diabetes were 8.3 times higher (OR: 58.27; $95 \% \mathrm{CI}, 6.69,10.21$ ) among women and 9.4 times higher (OR: 59.41; 95\% CI, 7.46, 11.87) among men aged more than 40 years. ${ }^{[8]}$ Reports indicate that males show higher prevalence of diabetes in the age group above 60 years while in females, it is between 51 and 60 years. ${ }^{[22]}$ This gender difference in prevalence of diabetes may be due to lower insulin action in young women than men as observed in few studies among Caucasians (101;102). Table 1 summarizes gender-specific prevalence of diabetes in India. . $^{4,23-34]}$

The regional disparities in the observed diabetes prevalence rates can be attributed to different distributions of risk factors such as BMI, obesity, physical activity, dietary patterns, and literacy levels. Obesity is positive predictor for diabetes in both males and females. At a BMI of 24 $\mathrm{kg} / \mathrm{m}^{2}$, the proportion of Asian men and women with diabetes was $5 \%$ each. For a waist circumference of 90 $\mathrm{cm}$ or waist-hip-ratio (WHR) of 0.9 , the proportion of Asian men with diabetes was 6\%35. ${ }^{[35]}$ A study in urban slum population from Northern India reported higher prevalence of obesity, as classified by BMI in females compared to males (15.6\%; 95\% CI, 10.7-22.3 vs. 13.3\%; 95\% CI, 8.5-19.5). ${ }^{[36]}$ According to the National Family Health Survey data, the prevalence of obesity in urban women increased from $9.4 \%$ in 1998-1999 to $24 \%$ in $2005-2006 .{ }^{137]}$ Recent findings indicate that the "thin-fat phenotype" (Asian Indian Phenotype) seen in Indians is one of the predominant risk factors for the development of diabetes. Given the pace of transition over the last two decades, a strong evidence linking the thin-fat phenotype to an environmental and lifestyle phenomenon particularly in migrating population has been observed in Indian population making them more vulnerable to diabetes compared to people from other origins. ${ }^{[38]}$

\begin{tabular}{|c|c|c|c|c|}
\hline \multirow[t]{2}{*}{ Author } & \multirow[t]{2}{*}{ Location } & \multicolumn{3}{|c|}{ Percentage of prevalence of diabetes } \\
\hline & & Male & Female & Overall \\
\hline Zargar et al. 2000 & Kashmir & 3.5 & 4.5 & 4.0 \\
\hline Misra et al. 2001 & South Delhi & 11.2 & 9.9 & 10.3 \\
\hline Basavanagowdappa et al. 2005 & Karnataka, Mysore & 4.58 & 2.66 & 3.77 \\
\hline Deo et al. 2006 & Malwan, Maharashtra & 9.2 & 9.9 & 9.3 \\
\hline Menon et al. 2006 & Kerala & 8.7 & 9.2 & 9.0 \\
\hline Chow et al. 2006 & Andhra Pradesh & 14.3 & 12 & 13.2 \\
\hline Balagopal et al. 2008 & Tamil Nadu & 6.2 & 4.4 & 5.1 \\
\hline Ramachandran et al. 2008 & Tamil Nadu & 10.4 & 8.0 & 9.2 \\
\hline Khatib et al. 2008 & Wardha & 8.8 & 8.1 & 8.5 \\
\hline Vijayakumar et al. 2009 & Kerala & 16.5 & 13.5 & 12.5 \\
\hline Rao et al. 2010 & Karnataka & 18.8 & 14.4 & 16.0 \\
\hline Zaman et al. 2011 & Karnataka & 16.1 & 22 & 19.8 \\
\hline Ahmad et al. 2011 & Kashmir & 3.6 & 8.3 & 6.05 \\
\hline Radhakrishnan and Balamurugan 2013 & Tamil Nadu & 22.0 & 15.0 & 36.0 \\
\hline
\end{tabular}


Socioeconomic status

Although the healthcare access and utilization are high in diabetes population, the health status and outcomes are unsatisfactory in low-income communities. This can be attributed to socioeconomic status (SES) which is a major determinant of health and a significant contributor to health disparities. ${ }^{[39]}$ Unlike developed countries where the lower socioeconomic population strata have a high prevalence of diabetes, obesity, and other noncommunicable diseases (NCDs), an opposite trend is observed in developing countries with diabetes being the most prevalent among people with higher SES. Analysis of a cross-sectional epidemiological survey conducted on a representative sample of the population of Chennai in Southern India indicated prevalence rates of diabetes in low, intermediate, and high socioeconomic groups to be $12.0 \%, 18.4 \%$, and $21.7 \%$, respectively $(P<0.001)$. A significant increase in the risk of diabetes was found in people with higher SES (Intermediate SES: OR, 1.7 [CI, 1.2-2.3]; high SES: OR, 2.0 [CI, 1.4-2.9]). . ${ }^{\text {(40] }}$ This disparity may be partly attributed to differential purchasing ability and calories intake which seems particularly high among high-income groups compared to lower-income groups (LIGs) of the society. ${ }^{[23]}$

Nevertheless, it should also be noted that as a result of rapid epidemiological transition in India, there is now a convergence of the prevalence rates of diabetes in the low- and middle-income groups (MIG) and may, in fact, become higher in the LIG. In a recent study, the prevalence of self-reported diabetes among LIG increased more rapidly $(6.5-15.3 \%, 135 \%$ increase, $P<0.001)$ than among MIG (12.4-15.4\%, 24\% increase, $P=0.159)$ and became similar to that observed in MIG. ${ }^{[41]}$ Similarly, Bhojani et al. revealed that people living below the poverty line had significantly greater odds of reporting chronic conditions than people living above the poverty line $(\mathrm{OR}=3,95 \% \mathrm{CI}=1.5,5.8)^{[42]}$

An increasing trend in expenditure on diabetes care was also observed among urban and rural population. A significant increase in the proportion of income spent on diabetes care was observed among lowest economic group (34\% of income in 1998 vs. $24.5 \%$ in 2005 ) ( $P<0.01)$. After adjusting for inflation, an $113 \%$ increase in the annual cost of diabetes was observed between 1998 and 2005 in the urban population, indicating substantial economic burden on urban families in developing countries. ${ }^{[43]}$ This reversal of socioeconomic gradient for diabetes ${ }^{[41,42]}$ can have a serious economic impact on poorer sections of the society where $>40 \%$ of the population continue to live in extreme poverty on $<\$ 1.25 /$ day. $^{[44]}$
Income and household wealth

The association between social class and diabetes may be explained by considering income as an indicator of social class. ${ }^{[40]}$ In a study by Ramachandran et al., it was reported that urban cases had significantly higher family income (Rs. 100,000 vs. Rs. 36,000; P<0.001) and total mean expenditure on healthcare (Rs. 10,000 vs. Rs. 6260; $P<0.001)$ when compared to rural cases. ${ }^{[43]}$ However, evidence suggests that the mean income level had almost doubled both in the MIGs and in the LIGs, ${ }^{[41]}$ leading to considerable changes in lifestyle and dietary patterns. This, in turn, triggers the accumulation of several risk factors for diabetes such as physical inactivity, higher calorie intake, and increased BMI and blood pressure which in turn paves way obesity, a central independent risk factor for the development of diabetes. ${ }^{[8]}$ Obesity has shown a strong positive association with SES (income/household wealth) among women and men in India. ${ }^{[44]}$ In one study, per capita income was found to be a significant predictor for self-reported diabetes particularly among men with low SES $(P<0.05) .^{[42]}$ In the same study, it was reported that an increase in per capita income was positively associated with the use of private healthcare facilities. A cross-sectional survey that quantified the association between SES and diabetes using household wealth reported that diabetes prevalence increased with household wealth $(2.5 \%$ in richest vs. $0.4 \%$ in poorest). It was observed that for a one-quintile increase in household wealth, the overall OR for diabetes in India was 1.31 (95\% CI, 1.20-1.42) (Corsi et al. 2012). These data signify that SES associated with diabetes in India may be more closely related to increasing wealth and/or standard of living.

\section{Dietary patterns}

Evidence from several studies examining the role of diet and dietary patterns on the risk of diabetes in India has shown that diet is a specific contributor, independent of obesity in the pathogenesis of diabetes. ${ }^{[45-47]}$ It has been observed that higher intakes of carbohydrate, saturated fatty acids, and trans fatty acids and lower intakes of fiber and $\omega-3$ polyunsaturated fatty acids are associated with insulin resistance, which may be considered an important contributory factor for its high prevalence. ${ }^{[48]}$ Although the dietary pattern, eating, and methods of cooking vary in different parts of India, the traditional dietary pattern is being increasingly replaced with consumption of "modern" foods rich in polyunsaturated fat. ${ }^{[48,49]}$ An imbalance between calorie intake (excessive) and energy output (reduced) is the major reason behind the escalating obesity and diabetes epidemic worldwide. ${ }^{[50]}$ Moreover, Asian diet has higher glycemic index values resulting in higher area under curve for glucose excursion, with larger 
postprandial peaks contributing for increased diabetes susceptibility among Asian Indians. ${ }^{[51]}$ Evidence suggests that Asian Indians living in US maintaining Indian dietary habits have higher insulin levels, higher plasma glucose levels, and lower insulin binding to erythrocytes after a glucose load compared to Caucasoid Americans, suggesting an increased risk of developing type 2 diabetes mellitus. ${ }^{[52]}$

\section{Education/literacy levels}

Lack of awareness coupled with low literacy levels underestimates the actual prevalence of diabetes epidemic in India. It can be observed that due to lack of awareness, there is a substantial delay in diagnosis of diabetes and those with late diagnosis are already manifested with multiple diabetes related complications. Reports indicate at least 7-year difference in the age of diagnosis for diabetes between the highest educated and the least educated. ${ }^{[16]}$ Moreover, the awareness of diabetes and its complications was also lower than satisfactory among Indian patients with at least $25 \%$ of the population being unaware of a condition called diabetes as reported in CURES study. Although education was associated with increased levels of awareness, it was observed from CURES study that, alarmingly, only $42.6 \%$ of literates knew that diabetes was preventable and only $40.6 \%$ were aware that diabetes could lead to some organ damage. ${ }^{[53]}$ Furthermore, well-established myths and misconceptions associated with poor education and cultural beliefs among people with diabetes can have significant impact on the management strategies for diabetes in India. Myths, such as "eating more sugar causes diabetes, relating presence of diabetes to past sins and thinking that only spiritual treatment can cure it, diabetes is only a disease of the elderly, diabetes is contagious, and it is more prevalent in females," are usually deep seated in the society and are passed on from one generation to the next lower literacy levels; lack of awareness and strong beliefs in myths and misconceptions about diabetes even among literates can have a profound effect on diabetes management. This, in turn, reflects on the disease burden which is much larger than it appears. ${ }^{[54]}$

The recent estimates indicate that the ratio of unknown to known diabetes in rural areas is $3: 1$ compared to $1: 1$ in urban areas. ${ }^{[55]}$ This rising prevalence of diabetes in rural areas may be attributed to lack of universal screening methods ${ }^{[56]}$ and extremely low awareness. ${ }^{[57]}$ The IDF estimates that 1 in 2 adults with diabetes is undiagnosed worldwide. ${ }^{[6]}$

Family history of diabetes

Family history of diabetes may be considered a major determinant of diabetes, as Indians have a tendency to develop diabetes at a younger age and are subjected to a strong genetic predisposition. ${ }^{[40]}$ Evidence suggests that the prevalence of diabetes among offspring with one diabetic parent was $36 \%$ which increased to $54 \%$ when both parents had diabetes. ${ }^{[58]}$ Similarly, a prevalence rate of $62 \%$ and risk of $73 \%$ were reported when both parents had diabetes. ${ }^{[23]}$ In a recent study, it was observed that a majority of patients with diabetes $(63.86 \%)$ had a positive family history of diabetes, indicating that it could be a major contributing factor in causing diabetes in future generations who are currently not suffering with diabetes. ${ }^{[22]}$ Strong evidence for a significant association between the prevalence of diabetes and positive family history, observed in several studies, highlights a genetic contribution to the prevalent epidemic. Furthermore, the risk of diabetes in those with a positive family history is further increased with consanguinity (marriage among close relatives) which is a common practice in India (Cadiresearch.org).

\section{Migration}

Irrespective of whether migration is intercountry or within country (rural-to-urban), it is one of the major risk factors for diabetes. Evidence suggests that South Asian urban migrants showed 4 times high prevalence rates of diabetes than those of rural nonmigrants. ${ }^{[37]}$ Migration is often associated with reduced physical activity, faulty nutrition, and exposure to stress that are most likely to contribute to the higher levels of obesity and diabetes. Evidence suggests that the age and factory adjusted odds of obesity and diabetes were 2 -fold greater in migrants than rural men and women (Obesity: 37.8\% [95\% CI, 35.0-40.6] vs. $19.0 \%$ [95\% CI, 17.0-21.0]; diabetes: $14.3 \%$ [95\% CI, 12.2-16.4] vs. $6.2 \%$ [95\% CI, 5.0-7.4] respectively). ${ }^{[51]}$ Moreover, a significant correlation of duration of migration with waist size and high fat content in the $\operatorname{diet}(P<0.001)$ was observed that can contribute to higher risk of diabetes. ${ }^{[37]}$

\section{Urbanization}

The increased risk of diabetes and other NCD risk factors, including obesity, hypertension, glucose intolerance, and cardiovascular disease, can be attributed to sedentary lifestyle, genetic susceptibility, and environmental and lifestyle changes as a result of rapid socioeconomic growth and rural-to-urban migration. ${ }^{[4,59]}$ As in many Asian countries, the situation in India is more alarming as it is in a process of rapid urbanization which is expected to reach $46 \%$ by $2030 .{ }^{[60]}$ Increasing urbanization, changes in standards of living, dietary patterns, and sedentary life style are important risk factors for high prevalence of diabetes and also other NCDs. ${ }^{[7]}$ 
Moreover, urbanization may expose people to a number of challenges including long working hours and other urban stress making them vulnerable to diabetes. ${ }^{[3]}$ Excessive caloric intake (unhealthy eating patterns) combined with reduced energy output (reduced physical activity) leads to increased obesity and insulin resistance, which results in diabetes. As a result, alongside undernutrition, overnutrition is also emerging with the improvement in socioeconomic condition and increasing urbanization ${ }^{[1]}$ that can exert considerable negative impact on the nation's economy and health system. ${ }^{[62]}$

\section{Cultural habits}

Cultural habits play an important role in attitudes and beliefs toward diabetes management among people of South Asian origin. The scenario is particularly challenging in India, where wide variations in cultural practices and attitudes hamper appropriate diabetes prevention strategies. Besides lower awareness and gender-based differences in diabetes management, cultural factors such as ethnicity, customs, use of indigenous forms of medicine, dietary patterns, and fasting conditions play a significant role in the prevalence and management of diabetes care. Traditionally, Indian diets are rich in carbohydrates and sweets that have high percentage of saturated and trans fats, which are specific contributors for obesity and diabetes. In a recent study, researchers found that people who consumed white rice were more than 1.5 times likely to have diabetes than people who consumed the least amount of rice, and that with every 5.5 ounce-serving of white rice a person ate each day, the risk of diabetes increases by $10 \% .{ }^{[63]}$ This explains why in South India, where rice is traditionally consumed as only cereal, people are at a higher risk of developing diabetes. ${ }^{[2]}$ Gender-based difference in diabetes control is another example of cultural practices that impacts diabetes management. Women in Indian culture often attribute low priority to health and symptoms and present late for screening or diagnosis compared to men. ${ }^{[64]}$ Women are deprived of healthy diet and are placed secondary to men and children in the household food distribution. This often leaves them with diet deficient of micro- and macro-nutrients resulting in poorer rates of compliance to therapy. Moreover, cultural and social restrictions for physical activity seen in women prevent them from practicing self-care behaviors such as exercise. ${ }^{[37]}$ Lack of awareness and language barriers make them dependent on the male counterparts and at times may also impede them from visiting physician and seeking healthcare. [65] On the other hand, the considerable number of patients still depends on alternative folk medicine for diabetes despite not being patronized by evidence of effectiveness or safety. ${ }^{[59]}$ Often people in India observe fasting as part of their religious traditions during various times of the year. Management of diabetes in people observing fasting should be individualized and special precautions should be considered to avoid any glycemic emergency. ${ }^{[6]}$

\section{UNDERSTANDING THE SOCIODEMOGRAPHIC CONTEXT OF INDIA'S MASSIVE DIABETES BURDEN}

The solution to successfully managing diabetes lies at the intersection of lines of enquiry seeking to understand the socioeconomic, demographic, and biological factors which are driving the epidemic in the context of their impact on public health policy [Figure 2]. In the past two decades, India has witnessed a rapid rise in the prevalence of diabetes that "has gone beyond epidemic form to a pandemic one" which is most worrisome. Studies ascertaining both diagnosed and undiagnosed cases in India have unmasked an unexpectedly high number of people with diabetes, many of them in their productive age groups. ${ }^{[24,67]}$ In India, for every known diabetic, there is one unknown diabetic in urban population and 3 in rural population. ${ }^{[55]}$ The IDF estimates that approximately 36,000 adults, in India, remain undiagnosed with diabetes. ${ }^{[6]}$ Despite the fact that diabetes is one of the most challenging public health problems of the $21^{\text {st }}$ century, it remains underreported in India, partly because many people are unaware of the disease or do not seek medical advice unless they are presented with secondary complications.

A large population, increased life expectancy, high genetic predisposition, and ethnic susceptibility to

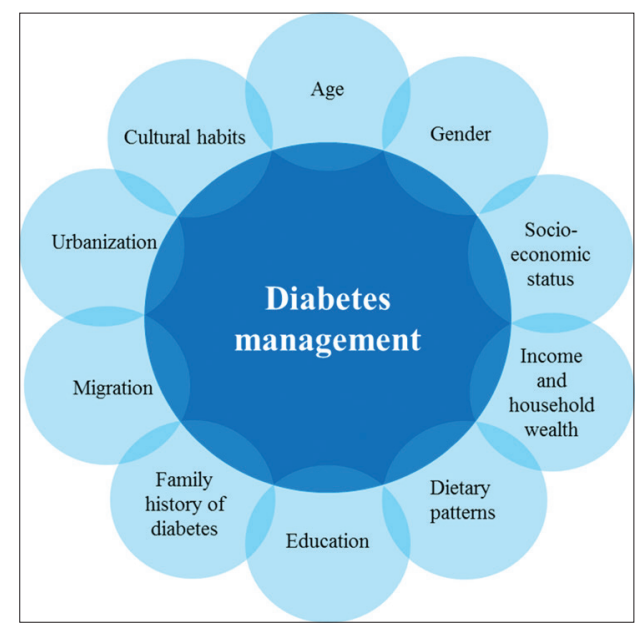

Figure 2: An inter-relation between sociodemographic parameters and diabetes management 
diabetes play a significant role in the rising prevalence of diabetes and its complications in India. The so-called "Asian Indian Phenotype" makes Indians more vulnerable to diabetes compared to people from other origins. Besides, other important predisposing factors for genetic susceptibility are increasing insulin resistance and obesity in Asians, particularly among women and children exposing them to higher risk of diabetes and its related complications later in life. ${ }^{[68]}$ The reason for this increased incidence of obesity may be attributed to changed lifestyle, increased consumption of calorie-rich food, and sedentary lifestyle particularly. Moreover, children who are obese at diagnosis with a positive family history of diabetes are at a greater risk of developing diabetes in future compared to those who are nonobese without family history. However, obesity, which was once disease of affluent, is now being observed even in lower socioeconomic strata in significant proportion. This clearly indicates that, irrespective of SES, this disease seems to be equally prevalent among high-, middle-, and low-income groups, being rightly called as "disease of profusion" rather than "disease of affluence" as it was a decade earlier.

The primary driver of the epidemic of diabetes in India is the rapid epidemiological transition associated with rapid urbanization, changes in traditional lifestyles, increased consumption of calorie-rich but micronutrient-poor food, and reduced physical activity as evident from the higher prevalence of diabetes in the urban population. Thus, the role of sociodemographic parameters in the rising prevalence of diabetes in India could not be underrated. In India, diabetes affects people in their economically productive age (20-45 years old) with an average age at onset of 42.5 years, a decade earlier than their European counterparts. ${ }^{[13,69]}$ If current trends of diabetes prevalence in this age group persist, there is likely to be a large group of people (who are currently in the work force and face diabetes) who will move into the geriatric age groups while increasing proportion of people in the working age will also have diabetes. As a result, financial output from working age population will be suboptimal (fewer resources due to diabetes) and the system will have to face the double burden of both geriatric diabetes and that in the working age groups (greater expenditure for diabetes). Thus, simultaneously diabetes will consume more resources while considerably impacting the ability to generate these financial resources unless timely policy measures address both preventive (future) and curative (current) aspects of diabetes management. Another disturbing trend that is being observed is the considerable decrease in the age at diagnosis where adult-onset diabetes has become increasingly common among adolescents and youth. Early onset of diabetes at a young age predisposes them to chronic long-term complications, severe morbidity, and early mortality resulting in serious economic implications due to loss of human resources. In addition, treatment of diabetes and its complications can induce severe financial burden on an individual and their families who are already burdened by psychological stress.

Despite an increase in literacy levels, projected in the future, there is likely to be no significant difference on the status of diabetes awareness in the population as seen from low levels of awareness seen in even literate cohorts of patients. In effect, more people will be affected with diabetes earlier but are not likely to be detected (and consequently targeted) and the resulting invisible mass of the diabetes burden holds the potential to scuttle policy efforts for commensurate interventions. The lack of awareness about diabetes, its causes and management in the Indian population is alarming. Such lack of awareness to different degrees exists across socioeconomic and demographic strata and is reflected in the large burden of undiagnosed diabetes. However, the bigger danger flowing from lack of awareness about the causes and management of diabetes is the process of myth-making associated with the disease. When myths substitute the sound information to satisfy public need information, they pass into the cultural practices of communities leading to incorrect practices and inaccurate information that in turn aggravates the disease burden. Even more dangerously, they may undermine the acceptability of accurate information about diabetes and persistence of imprudent diabetes management practices. Delaying formulation of comprehensive diabetes policy involving mass awareness may help prop up the strongest impediment in effectuating change - misconceptions and myths conflated with "traditional wisdom."

Despite studies showing no identifiable trends about the prevalence of diabetes in either gender, the importance of customizing diabetes management initiatives for women's participation is very important in the Indian context. Although several studies have been carried out to ascertain the prevalence of diabetes in India, they were either small-scale or regional not truly representing a nation as a whole underestimating the true magnitude of problem. This clearly implies that there is a need for larger studies in more diverse population for any meaningful evaluation of disease epidemiology. 


\section{What POLICIES ARE NeEDED tO PREVENT DIABETES? POLICY CHOICES AND ROLE OF POLICYMAKERS}

As India is slowly gaining control over the communicable diseases, the incidence and prevalence of NCDs particularly obesity, diabetes mellitus, and hypertension have increased rapidly reaching pandemic proportion. ${ }^{\text {[70] }}$ Despite the fact that India accounts for $16.7 \%$ of the world's diabetes, ${ }^{[6]}$ there have been no efforts to generate nation-wide data on the quality of diabetes care and there is no translational research to turn knowledge into action.

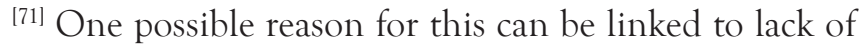
effective national surveillance system to monitor and implement preventive strategies by the government and civil society. Although India's Ministry of Health and Family Welfare (MHFW) did conduct surveys monitoring the spread of type 2 diabetes, no formal prevention and treatment policies were implemented to contain the disease. ${ }^{\text {[72] }}$ The National Rural Health Mission started by MHFW in 2005 did try to work within state in providing screening, treatment for diabetes, as well as preventive information; however, the program needs further strengthening and expansion to reach more of the population. ${ }^{[73]}$ Realizing the high prevalence of NCD risk factors in India, in 2008, MHFW enacted a pilot program, the National Program for Prevention and Control of Cancer, Diabetes, Cardiovascular Diseases and Stroke with an aim to prevent and control common NCDs through behavior and lifestyle changes, and to provide early diagnosis and management of common NCDs at various government health facilities. ${ }^{[74]}$ Nevertheless, these efforts have not been able to check rising burden of diabetes due to lack of effective implementation that is often limited by resources and capacity. For favorable outcomes from these healthcare programs, a stronger commitment on the part of government is required for planning and successful implementation at national level and to guide an effective policy. There is a need to establish new, or strengthen existing, national health policies and plans with broader multisectoral frameworks for the prevention and control of diabetes.

The policymakers and other stakeholders including private, nongovernmental organizations (NGOs), academicians/ researchers, health professionals, and media play a crucial role in the development and successful implementation of policies that are focused on prevention and control of diabetes. ${ }^{[72]}$ The policies can help in creating an environment that empowers and encourages individuals, families, and communities to prevent and manage diabetes optimally. Adopting an advocacy strategy that focuses on developing broad-based political platform for diabetes should be considered. Political Parties should be involved in promoting attention towards diabetes for public awareness. Similar strategies have been adopted by Parliamentary diabetes support groups in the US, Australia, and United Kingdom. Another strategy is to move from health policy to "health in all policies." ${ }^{\text {"75] }}$ It involves influencing other public policies governing trade, taxation, education, agriculture, advertising, urban development, workplace design and work practices, food production, storage, distribution, and pharmaceutical production that promote healthy lifestyle changes to help prevent or delay onset of diabetes. The WHO's "Global Diabetes Plan" recommends implementation of "health in all policies" approach with an aim to assess the health impact of all new policies on risk factors for diabetes and other NCDs when making infrastructure investments and designing and enacting new policies. ${ }^{[76]}$ "Adelaide Statement" was a joint initiative between WHO and the Government of South Australia which proposed tools and instruments to support governments in building "health in all policies." ${ }^{[77]}$

However, in a resource-limited country like India, a comprehensive approach involving both public and private sectors is required for the prevention and control of diabetes, and for the reduction of modifiable risk factors. It remains for policymakers to make diabetes a public health issue and sensitize communities on diabetes prevention by creating a political will for diabetes action. Policymakers should be involved in the development and implementation of a comprehensive policy and plan that not only integrates diabetes into national health development plan but also reorient and strengthen the existing health system enabling them to respond more effectively. ${ }^{[76]}$ A comprehensive assessment on the enactment of the national policy and its impact on the disease should be a mandate with the effective involvement of different government sectors. When necessary, these policies should be reviewed and strengthened to make it more effective in reducing modifiable risk factors and their determinants. ${ }^{[76]}$

Policymakers should consider revision of Indian dietary guidelines based on evidence that reflects principles of chronic disease prevention, food availability, and affordability, thus promoting good dietary habits in prevention of diabetes. ${ }^{[78]}$ Policies should be framed that focus on providing farmers with subsidies to grow vegetables and fruits ensuring increased accessibility and affordability of healthy foods. For instance, the women, infant, and children Project "FRESH" by the 
Michigan Department of Community Health is one such nutrition program that makes fresh produce available to low-income, nutritionally at risk consumers. Government policies that promote healthy lifestyles and food choices should be encouraged as seen in Mauritius and Poland. Government's policy to substitute high saturated fat palm oil with unsaturated soybean oil as main cooking oil medium led to $15 \%$ decline in cholesterol level among Mauritius population. Similarly, Poland's decision to liberalize import policy on vegetable oils, fruits, and vegetables and removal of subsidies on animal-based dairy products led to substitution of saturated fats by unsaturated fats, resulting in reduced cardiovascular mortality. Brazil spends around $70 \%$ of the school meals program's budget on fresh vegetables, fruits and minimally processed foods encouraging healthy food habits among school children. ${ }^{[79-81]}$ A recent economic-epidemiologic modeling study in India suggests that sugar-sweetened beverage (SSB) taxation at a high tax rate could mitigate rising obesity and type 2 diabetes in India among both urban and rural subpopulations. The study estimated that a $20 \%$ SSB tax could result in $3.0 \%$ reduction in overweight and obesity prevalence while the incidence of type 2 diabetes could be reduced by $1.6 \%$ among various Indian subpopulations over the period of 2014-2023. [82]

However, the major challenge faced by the government of India is to develop cost-effective strategies to prevent diabetes. Although the MHFW claims that diabetic medication is "essential medicine," it is only available to middle- and upper-income classes who can purchase insulin, needles, and oral pills from pharmacies and clinics. ${ }^{[16]}$ This is in sharp contrast to what was seen in Brazil which has been committed to universal access to medicine as a "human right" by freely distributing all type 2 diabetic medications such as metformin and glibenclamide pills, and supplies, such as needle pens, for free at local clinics and pharmacies. Consequently, in 2012, around 13.8 million individuals with diabetes received free diabetic medication. ${ }^{[81]}$ To provide universal access to medicine in India, there is an imperative need for social health movements that would influence political will seeking to create constitutional amendments in this direction.

Policies such as the National Urban Renewal Mission ${ }^{[83]}$ that creates areas in every community for increased physical activity by supporting the design and construction of bicycle lanes and pedestrian paths need to be strengthened. Such policies contribute to increased physical activity and weight reduction that can reduce the risk of diabetes and its risk factors such as obesity and hypertension.
Another alternative is to provide monetary incentives for prevention of diabetes as demonstrated in the "Lose Your Weight in Gold" campaign in Dubai. The initiative taken by the Dubai Municipality offered its participants at least a gram of gold for every kilogram they lost. Authorities seeking to raise awareness on rising obesity rates across the Gulf region initiated this campaign which drew in hundreds of people struggling with lifestyle-related diseases such as adult-onset diabetes and obesity, seeking to lose weight for a gold pay-out (http://www.thenational.ae/ uae/). Policies that promote or adopt healthy behaviors should be encouraged. Combining these programs with financial incentives would encourage people to engage more actively resulting in not only improved health outcomes but also reduction in total healthcare cost. ${ }^{[84]}$ For instance, the "Rewards for Health" program implemented by UnitedHealth Group, US, offers its employees the opportunity to earn points for specific health actions such as health screening or meeting certain targets such as BMI reductions and qualify for insurance premium reductions of up to $\$ 1,200$ per family per year (http://www.uhc.com).

In view of the current diabetes burden in India, a national policy with a framework based on overall prevention and management of diabetes should be developed. The policy should encompass vital strategic interventions including advocacy, resource mobilization and prioritization, capacity building, and partnerships and collaborations. The policy should promote advocacy strategy that focuses on creating common platform to address the determinants of diabetes and its associated complications by making it everyone's business and combine the notions of individual, community, social, corporate, and government responsibility. The policy should empower individuals, families, and communities to prevent and manage diabetes optimally and encourage full engagement of all levels and facets of society in taking responsibility for prevention and management of diabetes. To achieve this, diabetes management should be integrated into primary healthcare programs by creating awareness through education and training. Making best use of the available resources while setting clear and rational priorities can help in effective allocation of existing resources and to reduce duplication. Setting up of national and local priorities also helps in identifying what is required, what can be done and to what extent. Government, NGOs, and funding agencies should be involved in the adequate allocation of resources for diabetes. Health systems should be made more responsive to diabetes through capacity building that involves improving infrastructure and adequate medical supplies, improving diagnostic services and provision of necessary protocols and standards. The 
physicians and nurses should be trained and should be provided with clinical guidelines and protocols making them professionally competent to tackle diabetes. Appropriate information systems that are constantly monitored and evaluated at all levels of healthcare should be developed. Public-private partnerships are necessary not only for successful implementation of a policy but also to address the institutional capacity for strengthening public health training and research. Private sectors can aid in implementation of prevention-oriented programs through collaboration with government agencies and provide funding and expertise in control and management of diabetes. However, it is with the policymakers and government that are equipped with powerful tools of legislation, regulation, and taxation, to enact social policies and add voices from other sectors of the society that can serve to turn the tide of diabetes in India.

\section{CONCLUSION}

The prevalence of diabetes and its associated risk factors are high across a range of sociodemographic groups in India. The early onset of diabetes in productive age groups can have significant economic, societal, clinical, and individual impact. Representing a major shift in India's burden of disease, identification of predominant risk factors and sociodemographic patterns of the disease are important to design and implement current and future strategies for primary prevention and management of diabetes and its complications. Comprehensive multisectoral actions prioritizing identification of risk factors, early diagnosis, and effective implementation of cost-effective interventions can curb the epidemic of diabetes. There is an imperative need for a multifaceted approach for implementation of evidence-based policies, involving various departments of the government and nongovernmental agencies are required to address both preventive and curative aspects of diabetes management. These policies should ensure effective surveillance, increase access to affordable and essential medicines, and provide universal health coverage with an objective to decease economic burden on the individual, community, and nation as a whole. Policymakers should take lead role in the development or strengthening of the existing policies and see to that they are not only implemented but also evaluated for their effectiveness. A strong commitment from both public and private sectors toward implementation and intensifying population-based prevention strategies through proven programs and policies is required to address the growing burden of diabetes.

\section{Acknowledgments}

The authors would like to thank the Jeevan Scientific Technology Limited, Hyderabad, India, for providing medical writing assistance in the development of this manuscript.

Financial support and sponsorship

Nil.

\section{Conflicts of interest}

There are no conflicts of interest.

\section{REFERENCES}

1. Pradeepa R, Prabhakaran D, Mohan V. Emerging economies and diabetes and cardiovascular disease. Diabetes Technol Ther 2012;14 Suppl 1:S59-67.

2. Ramachandran A, Snehalatha C, Kapur A, Vijay V, Mohan V, Das AK, et al. High prevalence of diabetes and impaired glucose tolerance in India: National Urban Diabetes Survey. Diabetologia 2001;44:1094-101.

3. Jayawardena R, Ranasinghe P, Byrne NM, Soares MJ, Katulanda P, Hills AP. Prevalence and trends of the diabetes epidemic in South Asia: A systematic review and meta-analysis. BMC Public Health 2012;12:380.

4. Ramachandran A, Mary S, Yamuna A, Murugesan N, Snehalatha C. High prevalence of diabetes and cardiovascular risk factors associated with urbanization in India. Diabetes Care 2008;31:893-8.

5. Colagiuri S, Borch-Johnsen K, Glümer C, Vistisen D. There really is an epidemic of type 2 diabetes. Diabetologia 2005;48:1459-63.

6. International Diabetes Federation. Diabetes Atlas. $7^{\text {th }}$ edn.: International Diabetes Federation, 2015.

7. Ramachandran A, Snehalatha C, Shetty AS, Nanditha A. Trends in prevalence of diabetes in Asian countries. World J Diabetes 2012;3:110-7.

8. Agrawal S, Ebrahim S. Prevalence and risk factors for self-reported diabetes among adult men and women in India: Findings from a national cross-sectional survey. Public Health Nutr 2012;15:1065-77.

9. Kinra S, Bowen LJ, Lyngdoh T, Prabhakaran D, Reddy KS, Ramakrishnan L, et al. Sociodemographic patterning of non-communicable disease risk factors in rural India: A cross sectional study. BMJ 2010;341:c4974.

10. Available from: http://www.censusindia.gov.in/Census_And_You/ age_structure_and_marital_status.aspx. [Last accessed on date 2016 Jul 10].

11. Basu R, Breda E, Oberg AL, Powell CC, Dalla Man C, Basu A, et al. Mechanisms of the age-associated deterioration in glucose tolerance: Contribution of alterations in insulin secretion, action, and clearance. Diabetes 2003;52:1738-48.

12. Basu R, Dalla Man C, Campioni M, Basu A, Klee G, Toffolo G, et al. Effects of age and sex on postprandial glucose metabolism: Differences in glucose turnover, insulin secretion, insulin action, and hepatic insulin extraction. Diabetes 2006;55:2001-14. Erratum in: Diabetes 2006;55:2665.

13. Qiao Q, Hu G, Tuomilehto J, Nakagami T, Balkau B, Borch-Johnsen $\mathrm{K}$, et al. Age-and sex-specific prevalence of diabetes and impaired glucose regulation in 11 Asian cohorts. Diabetes Care 2003;26:1770-80. 
14. World Health Organization. Diet, Nutrition and the Prevention of Chronic Diseases. Joint WHO. Improving the Built Environment in India. Preventing Chronic Diseases: A Vital Investment. WHO Report 2005. Geneva: World Health Organization; 2003.

15. ICMR. Assessment of Burden of NCDs. Indian Council of Medical Research; 2006.

16. Venkataraman K, Kannan AT, Mohan V. Challenges in diabetes management with particular reference to India. Int $\mathrm{J}$ Diabetes Dev Ctries 2009;29:103-9.

17. Anjana RM, Pradeepa R, Deepa M, Datta M, Sudha V, Unnikrishnan R, et al. Prevalence of diabetes and prediabetes (impaired fasting glucose and/or impaired glucose tolerance) in urban and rural India: Phase I results of the Indian Council of Medical Research-INdia DIABetes (ICMR-INDIAB) study. Diabetologia 2011;54:3022-7.

18. Mohan V, Deepa M, Deepa R, Shanthirani CS, Farooq S, Ganesan A, et al. Secular trends in the prevalence of diabetes and impaired glucose tolerance in urban South India - The Chennai Urban Rural Epidemiology Study (CURES-17). Diabetologia 2006;49:1175-8.

19. Kumpatla S, Michael C, Aravindalochanan V, Viswanathan V. Changing trend in one decade in the profile of newly diagnosed subjects with type 2 diabetes in India. Int J Diabetes Metab 2011;19:107-12.

20. Anjana RM, Ali MK, Pradeepa R, Deepa M, Datta M, Unnikrishnan R, et al. The need for obtaining accurate nationwide estimates of diabetes prevalence in India - Rationale for a national study on diabetes. Indian J Med Res 2011;133:369-80.

21. Available from: http://www.censusindia.gov.in/2016. [Last accessed on date $2016 \mathrm{Jul} 10]$.

22. Patil RS, Gothankar JS. Prevalence of type-2 diabetes mellitus and associated risk factors in an urban slum of Pune city, India. Natl J Med Res 2013;3:346-9.

23. Deo SS, Zantye A, Mokal R, Mithbawkar S, Rane S, Thakur K. To identify the risk factors for high prevalence of diabetes and impaired glucose tolerance in Indian rural population. Int $\mathrm{J}$ Diabetes Dev Ctries 2006;26:19-23.

24. Chow CK, Raju PK, Raju R, Reddy KS, Cardona M, Celermajer DS, et al. The prevalence and management of diabetes in rural India. Diabetes Care 2006;29:1717-8.

25. Zargar AH, Khan AK, Masoodi SR, Laway BA, Wani Al, Bashir MI, et al. Prevalence of type 2 diabetes mellitus and impaired glucose tolerance in the Kashmir Valley of the Indian subcontinent. Diabetes Res Clin Pract 2000;47:135-46.

26. Basavanagowdappa H, Prabhakar AK, Prasannaraj P, Gurudev KC, Virupaksha, Suma. Study of prevalence of diabetes mellitus and impaired fasting glucose in a rural population. Int $\mathrm{J}$ Diabetes Dev Ctries 2005;25:98-101.

27. Menon VU, Kumar KV, Gilchrist A, Sugathan TN, Sundaram KR, Nair V, et al. Prevalence of known and undetected diabetes and associated risk factors in central Kerala - ADEPS. Diabetes Res Clin Pract 2006;74:289-94.

28. Balagopal P, Kamalamma N, Patel TG, Misra R. A community-based diabetes prevention and management education program in a rural village in India. Diabetes Care 2008;31:1097-104.

29. Khatib NM, Quazi ZS, Gaidhane AM, Waghmare TS, Goyal RC. Risk factors of type-2 diabetes mellitus in rural Wardha: $A$ community based study. Int J Diabetes Dev Ctries 2008;28:79-82.

30. Vijayakumar G, Arun R, Kutty VR. High prevalence of type 2 diabetes mellitus and other metabolic disorders in rural Central Kerala. J Assoc Physicians India 2009;57:563-7.

31. Rao CR, Kamath VG, Shetty A, Kamath A. A study on the prevalence of type 2 diabetes in coastal Karnataka. Int J Diabetes Dev Ctries 2010;30:80-5.

32. Zaman FA, Pal R, Zaman GS, Swati IA, Kayyum A. Glucose indices, frank and undetected diabetes in relation to hypertension and anthropometry in a South Indian rural population. Indian J Public Health 2011;55:34-7.

33. Radhakrishnan S, Balamurugan S. Prevalence of diabetes and hypertension among geriatric population in a rural community of Tamil Nadu. Indian J Med Sci 2013;67:130-6.

34. Ahmad J, Masoodi MA, Ashraf M, Rashid R, Ahmad R, Ahmad A, et al. Prevalence of diabetes mellitus and its associated risk factors in age group of 20 years and above in Kashmir, India. Al Ameen J Med Sci 2011;4:38-44.

35. Obesity in Asia Collaboration, Huxley R, Barzi F, Lee CM, Lear S, Shaw J, et al. Waist circumference thresholds provide an accurate and widely applicable method for the discrimination of diabetes. Diabetes Care 2007;30:3116-8.

36. Misra A, Pandey RM, Devi JR, Sharma R, Vikram NK, Khanna N. High prevalence of diabetes, obesity and dyslipidaemia in urban slum population in Northern India. Int J Obes Relat Metab Disord 2001;25:1722-9.

37. Misra A, Shrivastava U. Obesity and dyslipidemia in South Asians. Nutrients 2013;5:2708-33.

38. Kurpad AV, Varadharajan KS, Aeberli I. The thin-fat phenotype and global metabolic disease risk. Curr Opin Clin Nutr Metab Care 2011;14:542-7.

39. Onwudiwe NC, Mullins CD, Winston RA, Shaya FT, Pradel FG, Laird A, et al. Barriers to self-management of diabetes: A qualitative study among low-income minority diabetics. Ethn Dis 2011;21:27-32.

40. Skar M, Villumsen AB, Christensen DL, Petersen JH, Deepa M, Anjana RM, et al. Increased risk of type 2 diabetes with ascending social class in urban South Indians is explained by obesity: The Chennai urban rural epidemiology study (CURES-116). Indian J Endocrinol Metab 2013;17:1084-9.

41. Deepa M, Anjana RM, Manjula D, Narayan KM, Mohan V. Convergence of prevalence rates of diabetes and cardiometabolic risk factors in middle and low income groups in urban India: 10-year follow-up of the Chennai Urban Population Study. J Diabetes Sci Technol 2011;5:918-27.

42. Bhojani U, Beerenahalli TS, Devadasan R, Munegowda CM, Devadasan N, Criel B, et al. No longer diseases of the wealthy: Prevalence and health-seeking for self-reported chronic conditions among urban poor in Southern India. BMC Health Serv Res 2013;13:306.

43. Ramachandran A, Ramachandran S, Snehalatha C, Augustine C, Murugesan N, Viswanathan V, et al. Increasing expenditure on health care incurred by diabetic subjects in a developing country: A study from India. Diabetes Care 2007;30:252-6.

44. Corsi DJ, Subramanian SV. Association between socioeconomic status and self-reported diabetes in India: A cross-sectional multilevel analysis. BMJ Open 2012;2. pii: E000895.

45. Mitra A, Bhattacharya D. Effects of overall consumption, dietary patterns, cooking, on patients suffering from non insulin dependent diabetes mellitus. J Interacademicia 2005;9:635-42.

46. Mitra A, Basu B, Mukherjee S. Significance of different dietary habits in sections of Indian diabetics. J Hum Ecol 2009;26:89-98.

47. Salmerón J, Hu FB, Manson JE, Stampfer MJ, Colditz GA, Rimm EB, et al. Dietary fat intake and risk of type 2 diabetes in women. Am J Clin Nutr 2001;73:1019-26.

48. Mitra A, Bhattacharya D. Effect of fatty substances on health particularly to patients suffering from NIDDM and dyslipidaemia. J Interacademicia 2006;10:74-85.

49. Mitra A, Bhattacharya D. Role of retrograded starches particularly rice containing retrograded starches in non-insulin dependent diabetes mellitus. All India Seminar on Advances 
in Agro-Processing and Rural Empowerment. Agriculture Engineering Division, The Institution of Engineers (India), West Bengal State Center, Kolkata. 17-18 February, 2006.

50. Ebrahim S, Kinra S, Bowen L, Andersen E, Ben-Shlomo Y, Lyngdoh $\mathrm{T}$, et al. The effect of rural-to-urban migration on obesity and diabetes in India: A cross-sectional study. PLoS Med 2010;7:e1000268.

51. Henry CJ, Lightowler HJ, Newens K, Sudha V, Radhika G, Sathya RM, et al. Glycaemic index of common foods tested in the UK and India. Br J Nutr 2008;99:840-5.

52. Ramaiya KL, Kodali VR, Alberti KG. Epidemiology of diabetes in Asians of the Indian subcontinent. Diabetes Metab Rev 1990;6:125-46.

53. Mohan D, Raj D, Shanthirani CS, Datta M, Unwin NC, Kapur A, et al. Awareness and knowledge of diabetes in Chennai - The Chennai Urban Rural Epidemiology Study [CURES-9]. J Assoc Physicians India 2005;53:283-7.

54. Rai M, Kishore J. Myths about diabetes and its treatment in North Indian population. Int J Diabetes Dev Ctries 2009;29:129-32.

55. Mohan V, Mathur P, Deepa R, Deepa M, Shukla DK, Menon GR, et al. Urban rural differences in prevalence of self-reported diabetes in India - The WHO-ICMR Indian NCD risk factor surveillance. Diabetes Res Clin Pract 2008;80:159-68.

56. Todi S. Chronic hyperglycemia in critically ill: Another piece in the glycemic control puzzle. Indian J Crit Care Med 2014;18:3-5.

57. Pearson TA. Education and income: Double-edged swords in the epidemiologic transition of cardiovascular disease. Ethn Dis 2003;13 2 Suppl 2:S158-63.

58. Hussain A, Rahim MA, Azad Khan AK, Ali SM, Vaaler S. Type 2 diabetes in rural and urban population: Diverse prevalence and associated risk factors in Bangladesh. Diabet Med 2005;22:931-6.

59. Singh P, Yadav RJ, Pandey A. Utilization of indigenous systems of medicine and homoeopathy in India. Indian $\mathrm{J}$ Med Res 2005;122:137-42.

60. World Health Organization. Demographic trends. In Health Situation in the South-East Asia Region 1998-2000. Regional Office for South East Asia, New Delhi; 2002. p. 17-30.

61. Khongsdier R. Malnutrition, social inequality and natural selection in human populations. J Hum Ecol 2006;14:53-67.

62. Popkin BM. The nutrition transition: An overview of world patterns of change. Nutr Rev 2004;62 (7 Pt 2):S140-3.

63. Hu EA, Pan A, Malik V, Sun Q. White rice consumption and risk of type 2 diabetes: Meta-analysis and systematic review. BMJ 2012;344:e1454.

64. Rani M, Bonu S. Rural Indian women's care-seeking behavior and choice of provider for gynecological symptoms. Stud Fam Plann 2003;34:173-85.

65. Shrestha AD, Kosalram K, Gopichandran V. Gender difference in care of type 2 diabetes. JNMA J Nepal Med Assoc 2013;52:245-50.

66. Ganie MA, Koul S, Razvi HA, Laway BA, Zargar AH. Hyperglycemic emergencies in Indian patients with diabetes mellitus on pilgrimage to Amarnathji yatra. Indian J Endocrinol Metab 2012;16 Suppl 1:S87-90.

67. Joshi SR, Saboo B, Vadivale M, Dani SI, Mithal A, Kaul U, et al. Prevalence of diagnosed and undiagnosed diabetes and hypertension in India - Results from the Screening India's Twin Epidemic (SITE) study. Diabetes Technol Ther 2012;14:8-15.

68. Bajaj S, Jawad F, Islam N, Mahtab H, Bhattarai J, Shrestha D, et al. South Asian women with diabetes: Psychosocial challenges and management: Consensus statement. Indian J Endocrinol Metab 2013;17:548-62.

69. Mather HM, Keen $\mathrm{H}$. The Southall Diabetes Survey: Prevalence of known diabetes in Asians and Europeans. Br Med J (Clin Res Ed) 1985;291:1081-4.

70. Shriraam V, Mahadevan S, Anitharani M, Selvavinayagam, Sathiyasekaran B. National health programs in the field of endocrinology and metabolism - Miles to go. Indian J Endocrinol Metab 2014;18:7-12.

71. Arunachalam S, Gunasekaran S. Diabetes research in India and China Today: From literature-based mapping to health - Care policy. Curr Sci 2002;82:1086-97.

72. Siegel K, Narayan KM, Kinra S. Finding a policy solution to India's diabetes epidemic. Health Aff (Millwood) 2008;27:1077-90.

73. Bhojani U, Thriveni BS, Devadasan R, Munegowda CM, Devadasan AN, Criel B, et al. Challenges in organizing quality diabetes care for the urban poor: A local health system perspective. BMC Proceedings 2012 6(Suppl 5):O13.

74. Ministry of Health and Family Welfare. Pilot Phase of the National Programme for Prevention and Control of Diabetes, Cardio-Vascular Diseases, and Stroke Launched. Press Release. 4 January, 2008.

75. Puska P. Health in all policies. Eur J Public Health 2007;17:328.

76. Available from: http://www.idf.org/sites/default/files/Global Diabetes_Plan_Final.pdf. [Last accessed on date 2016 Jul 10].

77. World Health Organization. Adelaide Statement on Health in All Policies. Geneva: World Health Organization (WHO);2010.

78. Verma R, Khanna P, Mehta B. National programme on prevention and control of diabetes in India: Need to focus. Australas Med J 2012;5:310-5.

79. Available from: http://www.michigan.gov/documents/ MAPreportOct05_final_150918_7.pdf. [Last accessed on date 2016 Jul 10].

80. Coitinho D, Monteiro CA, Popkin BM. What Brazil is doing to promote healthy diets and active lifestyles. Public Health Nutr 2002;5:263-7.

81. João Leopoldo Oliveira Araujo, et al. Access to medicines for diabetes treatment in Brazil: evaluation of "health has no price" program. Diabetol Metab Syndr (2016) 8:35. DOI 10.1186/s13098016-0150-8

82. Basu S, Vellakkal S, Agrawal S, Stuckler D, Popkin B, Ebrahim S. Averting Obesity and Type 2 Diabetes in India through SugarSweetened Beverage Taxation: An Economic-Epidemiologic Modeling Study. PLoS Med 2014; 11(1): e1001582. doi:10.1371/ journal.pmed.1001582

83. Ministry of Urban Development, National Urban Transport Policy. New Delhi: Government of India; 2005.

84. Faghri PD, Li R. Effectiveness of financial incentives in a worksite diabetes prevention program. Open Obes J 2014;6:1-12. 